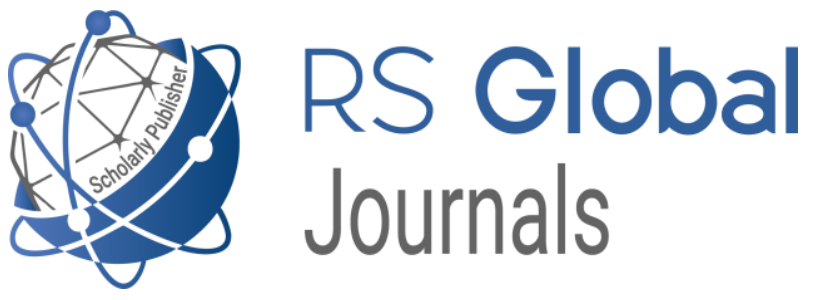

Scholarly Publisher

RS Global Sp. z O.O.

ISNI: 0000000484952390

Dolna 17, Warsaw, Poland 00-773

Tel: +48226022703

Email: editorial_office@rsglobal.pl

JOURNAL International Journal of Innovative Technologies in Social Science

p-ISSN $2544-9338$

e-ISSN

2544-9435

PUBLISHER

RS Global Sp. z O.O., Poland

ARTICLE TITLE

РОЛЬ РОМАНИСТИКИ ПЬЕТРО КЬЯРИ В

ARTICLE THLE

СТАНОВЛЕНИИ ИТАЛЬЯНСКОГО ЛИТЕРАТУРНОГО РОКОКО

$\operatorname{AUTHOR}(\mathbf{S})$

Данченко Мария Леонидовна

Maria Danchenko. (2021) The Role of Pietro Chiari's Novels in

ARTICLE INFO

Development of Italian Rococo in Literature. International Journal of Innovative Technologies in Social Science. 2(30). doi:

10.31435/rsglobal_ijitss/30062021/7596

DOI

https://doi.org/10.31435/rsglobal_ijitss/30062021/7596

RECEIVED

04 May 2021

ACCEPTED

07 June 2021

PUBLISHED

10 June 2021

LICENSE

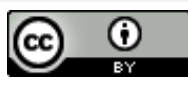

This work is licensed under a Creative Commons Attribution

4.0 International License.

(C) The author(s) 2021. This publication is an open access article. 


\title{
РОЛЬ РОМАНИСТИКИ ПЬЕТРО КЬЯРИ В СТАНОВЛЕНИИ ИТАЛЬЯНСКОГО ЛИТЕРАТУРНОГО РОКОКО
}

\author{
Данченко Мария Леонидовна, \\ Наииональный университет “Киево-Могилянская академия”, Киев, Украина, \\ ORCID ID: https://orcid.org/0000-0002-7846-9947
}

DOI: https://doi.org/10.31435/rsglobal_ijitss/30062021/7596

\begin{abstract}
ARTICLE INFO
Received 04 May 2021

Accepted 07 June 2021

Published 10 June 2021

\section{KEYWORDS}

Pietro Chiari, XVIII century, rococo, Italy, Venice.

ABSTRACT

This article explores a cultural significance of novel "La Filosofessa Italiana" written in 1753 Pietro Chiari and regarded the first Italian novel of early modern period. The objective of this research is to elucidate a formation of a new literary genre in Italian literature in XVIII century. In the following piece of research, the most outstanding European novels of XVIII century are examined in comparison with Pietro Chiari's novel. In the following work we analyze the influence that exercised P. Marivaux, S. Richardson, F. Prévost and D. Default's novels on the genesis of a new genre of Italian literary Rococo. In this article we investigate the details of the plot of "La Filosofessa Italiana" and explore the mental focus that was exposed by the first writer of Italian Rococo in this novel.
\end{abstract}

Citation: Maria Danchenko. (2021) The Role of Pietro Chiari's Novels in Development of Italian Rococo in Literature. International Journal of Innovative Technologies in Social Science. 2(30). doi: 10.31435/rsglobal_ijitss/30062021/7596

Copyright: (C) 2021 Maria Danchenko. This is an open-access article distributed under the terms of the Creative Commons Attribution License (CC BY). The use, distribution or reproduction in other forums is permitted, provided the original author(s) or licensor are credited and that the original publication in this journal is cited, in accordance with accepted academic practice. No use, distribution or reproduction is permitted which does not comply with these terms.

Введение. Современные ученые не сомневаются в существовании стиля рококо в итальянской литературе $(1,542)$. Основной проблемой в изучении данной темы является вопрос определения этого стиля. Большинство культурологов и теоретиков литературы определяют как рокайльные только те произведения итальянской литературы XVIII века, авторы которых выразительно подражают французской рокайльной тематике и повествовательной манере. При этом исследователи практически не предпринимают попыток вписать историю итальянской литературы первой половины XVIII века в общеевропейский контекст. Однако при параллельном изучении литературных процессов Италии и Франции с 1690-х по 1750-е годы становится очевидным факт их тесного взаимодействия. В частности, первые французские литературные сказки, которые считаются образцами стиля литературного рококо, были созданы на основе сказок народных во вторую половину 1690-х годов, а первым собрал и обработал сюжеты европейских народных сказок неаполитанец Джамбаттиста Базиле в 1632-1634 году.

При этом именно в 1690-е годы в Италии появились поэтические кружки-академии, так называемые «Аркадии», целью которых являлось реформирование тяжеловесного поэтического стиля маринизма, свойственного именно для литературного стиля барокко, таким образом, мы наблюдаем одновременную манифестацию стиля рококо в итальянской и французской литературе.

Формирование французской драматургии рококо происходило под теснейшим влиянием не только стилистики итальянского театра «del arte», но и при непосредственном участии драматургов-итальянцев в написании сценариев для спектаклей театра Первой (1660-1697) и Второй (1716-1762) Итальянской комедии. Особенно значительную роль в формировании стилистики французской драматургии зрелого рококо сыграло сотрудничество итальянского сценариста и теоретика драмы Луиджи Риккобони и прославленного французского писателя 
Пьера Мариво, продуктом которого стал знаменитый «мариводаж» - сюжетно-стилистическая манера, которая стала отличительной чертой литературы французского рококо. Луиджи Риккобони с конца 1720-х годов неоднократно возвращался в Италию с проектом реформы тамошнего архаичного театра по образцу французского, но его идеи не имели там успеха.

Настоящую реформу итальянского театра осуществил Карло Гоцци только в 1748 году, и его драматургия считается большинством культурологов одним из первых и классических образцов итальянского литературного рококо. Таким образом, факт наличия связей и взаимного влияния в итальянской и французской литературах с 1690-х по 1750-е годы в поэзии, малой прозе и драматургии является, с точки зрения большинства ученых, неоспоримым. Однако вопрос о наличии рококо в итальянской романной прозе остается открытым. Цель нашей статьи - исследовать культурологическую специфику итальянского романа 1750-годов с целью установления его стилистической принадлежности на материале произведения итальянского романиста Пьетро Кьяри (1712-1785) - «La Filosofessa Italiana» («Итальянская философка»), которое появилось в 1753 году и считается первым итальянским романом Нового времени.

П. Кьяри (1712-1785), уроженец Брешии, которая входила в состав Венеции, начинал свою карьеру как поэт, и был членом одной из аракадских Академий. С 1740-х годов он зарекомендовал себя как плодотворный драматург, но из-за конфликтов с К. Гольдони решил оставить эту сферу деятельности, и обратится к переводам английских и французских романов, которые пользовались в Венеции большим спросом. В частности, П. Кьяри перевел на итальянский язык романы «Памела» С. Ричардсона и «Жизнь Марианны» П. Мариво [6, 117]. Все изученные нами научные работы, посвященные специфике произведений П. Кьяри, делают акцент на вторичности романа «Итальянская философка». Все исследователи романа «Итальянская философка» изучают его, обязательно сравнивая с другими европейскими романами того же времени. Так, Синди Стэнфил сопоставляет произведение П. Кьяри с романами Д.Дефо «Молль Фландерс» 1722 года, С. Ричардсона «Памела» 1740 года, и романом «Жизнь Марианны» П. Мариво 1731-1745 годов [6,113]. Голландский же исследователь Мартин Хоген утверждает, что название романа П. Кьяри было прямо позаимствовано из названия роман аббата Прево «Кливланд, или английский философ» и даже усматривает прямое заимствование названия из порнографического романа «Тереза-философ», сочинение которого приписывают Б. д’Аржану, упоминая, впрочем, как и С. Стенфил, влияние и таких произведений, как «Марианна», «Памела», «Удачливый крестьянин», и даже «Комический роман» П. Скаррона, и «Жиль Блас» А. Лесажа $[4,7]$. Исследовательитальянец Альберто Дзава точно так же сравнивает роман П. Кьяри с произведениями Л. Стерна, С. Ричардсона, Д. Дефо, А. Лесажа, а затем изучает влияние роман П. Кьяри на произведение Д. Леопарди "La donna che non si trova" [7, 170].

В предисловии к роману «Итальянская философка» издатель книги Анджело Пазинелли следующим образом характеризирует роман: «Questo romanzo, che espongo alla luce del Pubblico, e tanto nuovo, che l'ho ricevuto de Parigi a foglio per foglio, secondo che usciva dal Torchio; e posso dire con tutta franchezza, che in Italia non l'ha ancora vedutto nessuno. Chi ebbe la benignità di mandarmelo con tanta attenzione, m'assicura; e puo per la capacità sua assicurarmelo; esser egli migliore di quanti ne sono usciti fin ora: piu instruttivo della Marianna, piu tenero della Pamela, piu intrecciato della Contadina, piu vago, e, diro cosi, filosofico del Filosofo Inglese, che pur fu ricevuto con tanto compatimento ${ }^{1} »$. Итак, мы видим, что сам издатель указывает на романы Ф. Прево, П. Мариво и С. Ричардсона как на произведения, которые имеют ближайшее сходство с романом П. Кьяри, но, тем не менее, смело заявляет о превосходстве именно произведения автора-итальянца. Эпиграф к роману звучит следующим образом: "Se un Ercole impazzi vestito in gonna, da uom filosofar puote una donna", что можно перевести как "Если обезумевший Геракл носил платье, то и женщина может быть философом” [2,8].

Сюжетной завязкой произведения являются мемуары женщины, которая решила поделиться с молодежью своим жизненным опытом и рассказать о пережитых ею в своей

\footnotetext{
1 Этот роман, который я предъявляю свету, столь нов, что я получал его из Парижа по страницам, как только они выходили из печатного станка; и со всей искренностью я готов заявить, что в Италии его еще не видел никто. Меня в этом уверил тот, кто имел милость отправить мне это произведения, и уверили в том меня также и способности сего благодетеля, что это произведение лучше всех тех, которые вышли до сего времени: более наставительное, чем «Марианна», более чувствительное, чем «Памела», с большим количеством хитросплетений, чем «Удачливый крестьянин», более изящное, и, можно сказать, более философическое, чем «Английский философ».
} 
молодости приключениях. Роман «Итальянская философка» представляет собой четырехтомное издание общим объемом около семисот страниц. Главная героиня - молодая девушка, итальянка по происхождению, носящая фамилию Д’Арвиль, с детства воспитывалась в монастыре для благородных девиц в Авиньоне, ничего не зная о своих родителях. Молодая особа хорошо владеет языками - итальянским, французским, английским и немецким, имеет талант к музыке и пению. Незадолго до своего совершеннолетия героиня получает неподписанное письмо от женщины, которая представляется ее матерью, хвалит ее успехи в обучении, и, вручая дочери в дар крупную сумму денег, призывает хранить молчание и не пытаться узнать подробности о своих родителях, обещая дочери, что их встреча состоится, когда для этого наступит время. Вместе с письмом для дочери мать отправляет послание и кошелек с золотом и настоятельнице монастыря. Последнее по случайности тоже попадает в руки героини, и она узнает о том, что ее мать обещает щедро вознаградить обитель, если ее дочь убедят принять там постриг. Девушка не имеет призвания к монашеской жизни, и не хочет становится монахиней. Внезапно в обители умирает мадмуазель де Ренн, подруга главной героини, и она знакомится с ее братом, графом ди Тренте, прибывшим на похороны. Молодые люди влюбляются друг в друга. После нескольких свиданий граф оставляет героине записку, в которой скупо уведомляет ее о своем отбытии на войну во Франции. Раздосадованная девушка уверена, что это - следствие тайных интриг ее матери. Мадемуазель Д’Арвиль сбегает из монастыря, переодевшись в мужское платье, в сопровождении доверенной служанки Селестины. Д’Арвиль выдает себя за мужчину аристократа графа Рикьяра, и решает отправится в Париж, а Селестина играет роль супруги графа. Для того, чтобы добыть средства для существования, героиня закупает в Лионе ткани и галантерею, собираясь выгодно продать их в столице. Тем временем слухи о побеге воспитанницы монастыря проникают в газеты, девушку усердно разыскивают, и эта история привлекает внимание общества. Селестина неожиданно умирает, и богатый лионский коммерсант, с которым Д’Арвиль успела свести знакомство, оказывает ей покровительство. Коммерсант получает из Авиньйона письмо от своего знакомого - графа Тренте, который разыскивает свою сбежавшую возлюбленную, и показывает графу Рикьяру полученную депешу. Девушка любит своего избранника, и даже тайно отправляет ему послание, но не считает возможным раньше времени раскрыть свое инкогнито. Покидая Лион, героиня поочередно посещает разные французские города, и знакомится там с аристократами, которые по случаю останавливаются в тамошних постоялых дворах. Один из них оказывается французским послом в Италии, и он принимает графа Рикьяра к себе на службу секретаря. Посол женат, и его супруга проявляет нежные чувства к некоему князю - своему бывшему жениху. Герцог просит своего секретаря присматривать за верностью супруги, подозревая, что князь имеет виды на получение его наследства в случае вдовства своей жены, но Д’Арвиль претит роль шпионки, и она рассказывает герцогине о данном ей поручении. Секретарь становится посредником между герцогиней и ее возлюбленным-князем. Одна из придворных дам герцогини, некая вдова, влюбляется в «графа Рикьяра» и всеми силами добивается у герцога согласия на брак, в том числе и по той причине, что уже ждет ребенка от другого мужчины и замужеством пытается спасти свою честь. По настоянию герцога Д'Арвиль соглашается на брак, но с ужасом обнаруживает, что почерк ее будущей супруги в точности соответствует тому, которым были написаны послания ее матери к ней же. Героиня проводит небольшое расследование, и убеждается, что ее матерью, скорее всего, является другая придворная дама герцогини, которая просила свою подругу писать компрометирующие письма вместо нее, чтобы избежать возможного разоблачения. В герцоге девушка распознает своего вероятного отца. Хозяин дома начинает подозревать о том, что его секретарь стал посредником между его супругой и князем, и граф Рикьяр впадает в немилость, так что начинает опасаться за собственную жизнь. Героине приходится срочно просить об отставке, идти на службу уже к князю, и ехать за ним в Париж, откуда она намеревается ехать на французский фронт, чтобы встретиться там с графом Тренте. На этом события первого тома заканчиваются.

Даже беглый пересказ сюжета произведения П. Кьяри позволяет отметить его оригинальность и отсутствие сюжетного сходства с любым из современных ему произведений. Особенно неудовлетворительным мы находим тот факт, что изучаемому нами произведению П. Кьяри исследователи приписывают сродство с целым рядом английских и французских романов, стиль написания которых делает их не только совершенно различными, но и подчас несопоставимым между собой. Так, С. Стенфилл, указывает на одновременное родство «Итальянской философки» с «Памелой» С. Ричардсона - английским сентиментальным 
романом 1740 года, романом в стиле рококо «Жизнь Марианны», П. Мариво который был написан между 1730 и 1740 годами, и комическим плутовским романом «Молль Фландерс» историей воровки, написанной Д. Дефо [6, 130]. Стоит отметить ту важную деталь, что, в отличии от пьес П. Кьяри, роман «Итальянская философка» написан на литературном итальянском языке без элементов венецианского диалекта вопреки тому, что писатель был именно из региона Венето, и роман был издан в Венеции. Следовательно, он был предназначен не только для читателей из всех областей Италии, но, как мы видим из предисловия издателя, имел огромный успех и в зарубежных странах. Пьетро Кьяри всячески пытается создать в данном романе своеобразный культурный фон, который можно охарактеризовать как общеевропейский. $\mathrm{K}$ примеру, он скрупулезно указывает, какие именно английские философские произведения и французские романы читает его героиня. В городе Труа Д'Арвиль посещает театральный спектакль, который играют именно актеры Итальянской комедии, и, более того, героиня выслушивает их подробные рассуждения о состоянии современного театра. Именно противостояние между итальянской и французской сюжетно-сценической техниками было одним из главных пунктов культурной повестки в Европе в третью четверть XVII первую половину XVIII века. При этом, всячески стремясь отдалить образ своей главной героини от типичной для барочного романа плутовки, автор упоминает об искреннем презрении и отвращении, которое испытывает изображающая мужчину девушка к актерам и их ремеслу.

Действие всего первого тома повествования занимает путешествие героини по разным французским городам, и на каждом этапе своего путешествия она приобретает новых знакомых или ценный опыт. Данная композиция сходна с сюжетом «Путешествия Телемака» Франсуа Фенелона, главный герой которого приобретает умения и опыт, необходимый для хорошего правителя государства, скитаясь по разным странам Средиземноморья в поисках своего отца. Если роман Ф. Фенелона был написан в 1699 году, то «Итальянская философка» 1753 года изображает тот же духовно-образовательный путь, только на этот раз его проходит женщина, обращаясь временами в мужчину и обретая себя как философа. Весьма необычной чертой «Итальянской философки» является тот факт, что главная героиня не просто переодевается в мужской костюм под давлением обстоятельств, но и является двуполым существом по сути. Свою философию Д’Арвиль практикует только в мужском облике, и последняя весьма проста она заключается в том, что смысл любой философии - применение здравого рассудка, и, по рассуждению главной героини, эту черту следует развивать как мужчинам, так и женщинам. Примечательным является и тот факт, что героиня не отказывается от своей женской роли, совершенно спокойно возвращаясь к ней, как только обстоятельства того требуют. Д'Арвиль эмансипирована, и считает, что итальянским женщинам необходимо образованию по образцу того, которое получают дамы во Франции “In Francia leggono piu' le donne, che gli uomini; perocchè essendo esse meno occupate di loro dagli affari civili, e domestici, hanno piu' tempo da coltivarsi colla lettura d'ingegno; dannogli quella tintura di varie cose morali, istoriche, geografiche, romazeche e civili..."1 [6, 266]. Героиня пылко любит графа ди Тренте, но в течении пяти лет без сожалений не видится со своим возлюбленным, ради которого сбежала из монастыря, и считает, что "se le Donne conoscessero i loro vantagi, non anojerebbero gli amanti a forza di lettere, d'ambasciate, di visite, e di voleri sempre vicini. Siccome l'abondanza sazia ne' cibi, cosi biene a noja, e si cangia in disprezzo la troppa domestichezza in amore" $[6,330] .^{2}$ Подобное поведение главной героини невообразимо для английского сентиментального романа XVIII века, хотя исследователи в изученных нами работах утверждают о том, что П. Кьяри имитировал именно стилистику последнего [5, 215]. Женские персонажи французских романов XVIII века, в частности, героиня романа «Тереза-философ» Буайе д’Аржана, ограничиваются отстаиванием права женщины быть свободной от религиозных догм и удовлетворять свои телесные потребности, но даже не выдвигают теоретической возможности равенства мужского и женского пола.

Выводы. Роман Пьетро Кьяри «Итальянская философка» по своим жанровостилистическим признакам не похож ни на один другой европейский роман XVIII века.

\footnotetext{
${ }^{1}$ Во Франции женщины читают больше, чем мужчины, потому что они не заняты в государственных или частных делах, и имеют больше времени для того, чтобы обучаться через чтение разумных книг: они дают им представление о моральных, исторических, географических, романных и мирских вещах...

2 «Если бы женщины знали о своих преимуществах, то они бы не докучали своим любовникам потоком писем, посланий, визитов, и не стремились бы постоянно иметь их при себе. Как еда утоляет голод, так и чрезмерная близость в любви создает скуку».
} 
Произведение Пьетро Кьяри отличает широта и масштабность действия, нехарактерная для камерной прозы XVIII века, но, в то же время, в нем полностью отсутствуют бурлеск, «плутовская» сюжетика и комизм. В то же время, главная героиня не является действующим лицом, классическим для просветительского романа воспитания, и не совпадает с персонажами либертенских повестей - она смела и уверенна в себе, борется с предрассудками косной общественной морали, но не противопоставляет себя социуму. В отличие от героев плутовского романа, главный персонаж «Итальянская философка» не преследует цели личного обогащения либо преуспеяния. Произведением, самым близким по сюжету к «Итальянской философке», является французский роман в стиле рококо «Жизнь Марианны», но его главная героиня - добродетельна и пассивна. Мадмуазель Д’Арвиль интересует именно реализация возможности для женщины заниматься мужскими профессиями и преуспевать в них на равных с мужчинами, поэтому автор облек свою героиню бигендерной сущностью - сюжетный ход, несвойственный для литературы Просвещения. Возможность моментального превращения женщины в мужчину, и наоборот, является чертой, свойственной именно для литературы рококо. Равенство мужской и женской идентичностей, и провозглашаемое героиней рассуждение о том, что философия правильной жизни - одинакова для мужчин и дам, делает роман Пьетро Кьяри «Итальянская философка» 1753 года первым образцом крупной прозы в стиле рококо в итальянской литературе.

\section{ЛИТЕРАТУРА}

1. Campanacci, I. (1986). Il Rococò Letterario. Studi e Prospettive (1960-1986). Lettere Italiane, 38(4), 542577. Retrieved from http://www.jstor.org/stable/26263928

2. Chiari, P. (1753) La filosofessa Italiana, o sia le avventure della marchesa N. N. Scritte in francese da lei medesima. Tomo primo. Retrieved from https://books.google.com.ua/books?id=wilYAAAAcAAJ\&printsec=fr ontcover\&dq=pietro+chiari+la+filosofessa+italiana\&hl=uk\&sa=X\&redir_esc=y\#v=onepage\&q=pietro\%20chiari $\% 201 \mathrm{a} \% 20$ filosofessa\%20italiana\&f=false

3. Clerici, L. (1996). L'ingegnosa Ricetta Dell'abate Chiari Romanziere. Belfagor, 51(4), 403-416. Retrieved from http://www.jstor.org/stable/26147163

4. Haugen M. W. (2015) Appropriating the Novel: Pietro Chiari's la Filosofessa Italiana. Forum for modern language studies, 51(2): 212-228. Retrieved from https://ntnuopen.ntnu.no/ntnuxmlui/bitstream/handle/11250/2392662/Appropriating\%2bthe\%2bNovel_peer-

reviewed $\% 2 \mathrm{bdraft} \% 2 \mathrm{bversion}$.pdf?sequence=3\&isAllowed=y

5. Singer, G. F. (2016) The Epistolary Novel: its origin, development, decline, and residuary influence. Retrieved from https://books.google.com.ua/books?id=nVIrEAAAQBAJ\&printsec=frontcover\&hl=ru\&source=gbs_ge_su mmary_r\&cad $=0 \# v=$ onepage $\& q \& f=$ false

6. Stanphill, S. (2018) Polemics and the Emergence of the Venetian Novel: Pietro Aretino, Pietro Chiari, and Carlo Gozzi. Retrieved from https://www.proquest.com/openview/9c0f67ab0fea162ab2642d5bfcb16303/1?pqorigsite $=$ gscholar $\&$ cbl $=18750 \&$ diss $=y$

7. Zava, A. (2014) Pietro Chiari e L'Itinerario del romanzo moderno italaino. In Commentari Dell'ateneo Di Brescia Per L'anno..., vol. anno 2009, pp. 169-178. Retrieved from https://core.ac.uk/download/pdf/53183203.pdf 